\title{
SISTEM WAKTU NYATA PENGUJIAN HAFALAN AYAT-AYAT SUCI AL QURAN SECARA EKSPONENSIAL DAN NONSINUSOIDAL
}

\author{
Fadlisyah', Wahyu Fuadi ${ }^{2}$, Kamilaini ${ }^{3}$ \\ Program Studi Teknik Informatika \\ Universitas Malikussaleh \\ Jl. Kampus Unimal Bukit Indah Blang Pulo
}

\begin{abstract}
Abstrak
Abstrak - Prinsip pengembangan perangkat lunak otomatisasi adalah selaras dengan prinsip-prinsip yang ditekankan pada era revolusi industri 4.0., artinya perangkat lunak pada era 4.0 sudah mampu meminimasir peran manusia baik dalam pengembangannya, kemampuan belajar, ataupun operasionaloperasional teknis lainnya. Untuk menjawab tantangan model 4.0, maka penelitian ini mengajukan sebuah algoritma yang robust dalam menguji hafalan-hafalan Qur'an secara digital. Pendekatan yang digunakan mewakili fungsi basis eksponensial dan nonsinusoidal yaitu berturut-turut Transformasi Mellin dan Walsh. Pengujian melibatkan 100 sampel para penghafal Qur'an, dengan masing masing unjuk kerja, 0,9 ditunjukan oleh penerapan Transformasi Mellin dan 0,82 dihasilkan oleh Transformasi Walsh. Untuk pengembangan sistem yang lebih tinggi keakuratannya dan lebih efisiensi pemakaian memori yang digunakan, penelitian menghasilkan saran penmbangunan model Fast Transform untuk kedua algoritma.
\end{abstract}

\section{Kata Kunci : Hafalan Qur'an, Mellin, Walsh}

\section{Pendahuluan}

Tidak dipungkiri lagi, bahwa peminatan terhadap hafalan $\mathrm{Al}$ Qur'an semakin banyak secara kuantitas dan mengalami perkembangan secara pesat dalam metode pendekatan 
hafalannya. hal ini dapat dilihat dengan tumbuh suburnya dengan mudah lembaga-lembaga tahfidz Qur'an. Setiap lembaga tahfidz Qur'an memiliki cara-cara sendiri dalam menerapkan praktek hafalan Qur'an kepada para santrinya, dan pastinya mereka dibimbing oleh seorang guru yang sudah menguasai Qur'an secara hafalan. Dengan peserta hafalan Qur'an yang cukup besar dan keterbatasan kemampuan pelayanan guru dalam waktu yang singkat, maka telah munculah permasalahan baru yang menarik untuk diangkat dan dicari solusi terapannya secara efisien dan hemat waktu. Maka penelitian yang diajukan adalah bagaimana membangun sebuah sistem pengujian hafalan Qur'an yang mengadopsi kemampuan hafalan guru untuk diterapkan sebagai pengawasan dan pengujian hafalan para peserta hafalan Qur'an.

Untuk membangun sebuah sistem hafalan Qur'an yang handal secara waktu-nyata maka diperlukan sebuah atau lebih algoritma. Dalam penelitian yang diajukan pada kesempatan ini, peneliti menggunakan dua pendekatan (1) Transformasi Mellin, dan (2) Transformasi Walsh. Adapun alasan pemilihan kedua algoritma ini adalah Transformasi Mellin lebih mewakili algoritma yang efisien yang bersifat eksponensial dan Transformasi Walsh mewakili algoritma yang berbasis non-sinusoidal, atau memiliki fungsi basis -1 dan 1 .

\section{a. Transformasi Mellin}

Transformasi bertujuan mengubah sinyal-sinyal digital dari domain waktu menjadi sinyal-sinyal pada domain frekuensi dengan formulasi berikut :

$$
\varphi(s)=\int_{x=0}^{N-1} x^{s-1} f(x) d x
$$

dimana

$$
\begin{array}{ll}
\varphi(s) & =\text { Transformasi Mellin } \\
s & =\text { indeks sinyal pada domain frekuensi } \\
N & =\text { total cacah sinyal } \\
x & =\text { indeks sinyal pada domain waktu }
\end{array}
$$


$f(x) \quad=$ nilai sinyal.

\section{b. Transformasi Walsh}

Tidak seperti transformasi yang dibahas sebelumnya yang memiliki fungsi basis bilangan pecahan antara selang -1 hingga 1 (sin dan cos), Transformasi Walsh memiliki sifat yang nonsinusoidal, atau dengan kata lain Transformasi Walsh memiliki fungsi basis -1 atau 1 .

Transformasi Walsh pada sinyal $\mathrm{f}(\mathrm{x})$ dinyatakan sebagai :

$$
W(u)=\frac{1}{N} \sum_{x=0}^{N-1} f(x) \prod_{i=0}^{n-1}(-1)^{b_{i}(x) b_{n-1-i}(u)}
$$

dengan $u=0,1,2, \ldots, N-1$ dan $x=0,1,2, \ldots, N-1$, dan nilai $n$ mengikuti aturan $N=2^{n}$.

Sebagai contoh jika $\mathrm{N}=8$ maka $\mathrm{n}=3$.

$b_{i}(x)$ menyatakan bit ke $\mathrm{i}$ dari bentuk biner $\mathrm{x}$, misal $\mathrm{x}=4$ atau secara biner $=100$, maka $b_{0}(x)=0, b_{1}(x)=0$, dan $b_{2}(x)=1$. Demikian juga berlaku untuk $b_{i}(u)$.

Fungsi basis Transformasi Walsh dinyatakan dengan formula berikut :

$$
g(x, u)=\prod_{i=0}^{n-1}(-1)^{b_{i}(x) b_{n-1-i}(u)}
$$

dan dari persamaan fungsi basis (kernel) Transformasi Walsh

\begin{tabular}{|c|c|c|c|c|c|c|c|c|}
\hline & 0 & 1 & 2 & 3 & 4 & 5 & 6 & 7 \\
\hline 0 & + & + & + & + & + & + & + & + \\
\hline 1 & + & + & + & + & - & - & - & - \\
\hline
\end{tabular}
untuk $\mathrm{N}=8$ akan dihasilkan nilai-nilai kernel berikut : 


\begin{tabular}{lllllllll}
\hline 2 & + & + & - & - & + & + & - & - \\
\hline 3 & + & + & - & - & - & - & + & + \\
\hline 4 & + & - & + & - & + & - & + & - \\
\hline 5 & + & - & + & - & - & + & - & + \\
\hline 6 & + & - & - & + & + & - & - & + \\
\hline 7 & + & - & - & + & - & + & + & - \\
\hline
\end{tabular}

Untuk mendapatkan sebuah nilai pada kernel, maka dengan cara perhitungan berikut, misalkan ambil kasus $\mathrm{u}=1$ dan $\mathrm{x}=4$, karena $\mathrm{N}=8$ maka $\mathrm{n}=3$.

biner $\mathrm{u}=1$ adalah 001

biner $\mathrm{x}=4$ adalah 100

maka

$$
\begin{aligned}
& b_{0}(u)=1, b_{1}(u)=0, \text { dan } b_{2}(u)=0 \\
& b_{0}(x)=0, b_{1}(x)=0, \text { dan } b_{2}(x)=1 \\
& g(x, u)=\prod_{i=0}^{n-1}(-1)^{b_{i}(x) b_{n-1-i}(u)} \\
& g(4,1)=\prod_{i=0}^{2}(-1)^{b_{i}(4) b_{n-1-i}(1)} \\
& g(4,1)=(-1)^{(0)(0)}(-1)^{(0)(0)}(-1)^{(1)(1)}=(-1)^{1}=-1
\end{aligned}
$$

Kasus lain misalkan $\mathrm{u}=4$ dan $\mathrm{x}=6$,

biner $\mathrm{u}=4$ adalah 100

biner $\mathrm{x}=6$ adalah 110

maka

$$
b_{0}(u)=0, b_{1}(u)=0, \text { dan } b_{2}(u)=1
$$




$$
\begin{aligned}
& b_{0}(x)=0, b_{1}(x)=1, \text { dan } b_{2}(x)=1 \\
& g(x, u)=\prod_{i=0}^{n-1}(-1)^{b_{i}(x) b_{n-1-i}(u)} \\
& g(6,4)=\prod_{i=0}^{2}(-1)^{b_{i}(6) b_{n-1-i}(4)} \\
& g(6,4)=(-1)^{(0)(1)}(-1)^{(1)(0)}(-1)^{(1)(0)}=(-1)^{0}=1
\end{aligned}
$$

Hitung Transformasi Walsh dari sinyal $f(x)=1,1,1,1,5,5,5,5$

Penyelesaian :

$$
\begin{aligned}
& \mathrm{W}(0)=\frac{1}{8}(1+1+1+1+5+5+5+5)=3 \\
& \mathrm{~W}(1)=\frac{1}{8}(1+1+1+1-5-5-5-5)=-2 \\
& \mathrm{~W}(2)=\frac{1}{8}(1+1-1-1+5+5-5-5)=0 \\
& \mathrm{~W}(3)=\frac{1}{8}(1+1-1-1-5-5+5+5)=0 \\
& \mathrm{~W}(4)=\frac{1}{8}(1-1+1-1+5-5+5-5)=0 \\
& \mathrm{~W}(5)=\frac{1}{8}(1-1+1-1-5+5-5+5)=0 \\
& \mathrm{~W}(6)=\frac{1}{8}(1-1-1+1+5-5-5+5)=0 \\
& \mathrm{~W}(7)=\frac{1}{8}(1-1-1+1-5+5+5-5)=0
\end{aligned}
$$

maka Transformasi Walsh dari sinyal $f(x)=1,1,1,1,5,5,5,5$ adalah $\mathrm{W}(\mathrm{u})=3,-2,0,0,0,0,0,0$. 


\section{Metode Penelitian}

\section{A. Skema Sistem}

Dalam penelitian yang diajukan untuk membangun sebuah sistem yang robust, maka diperlukan alur sistem atau skema. Skema sistem yang dibangun dilustrasikan pada gambar 5.1.

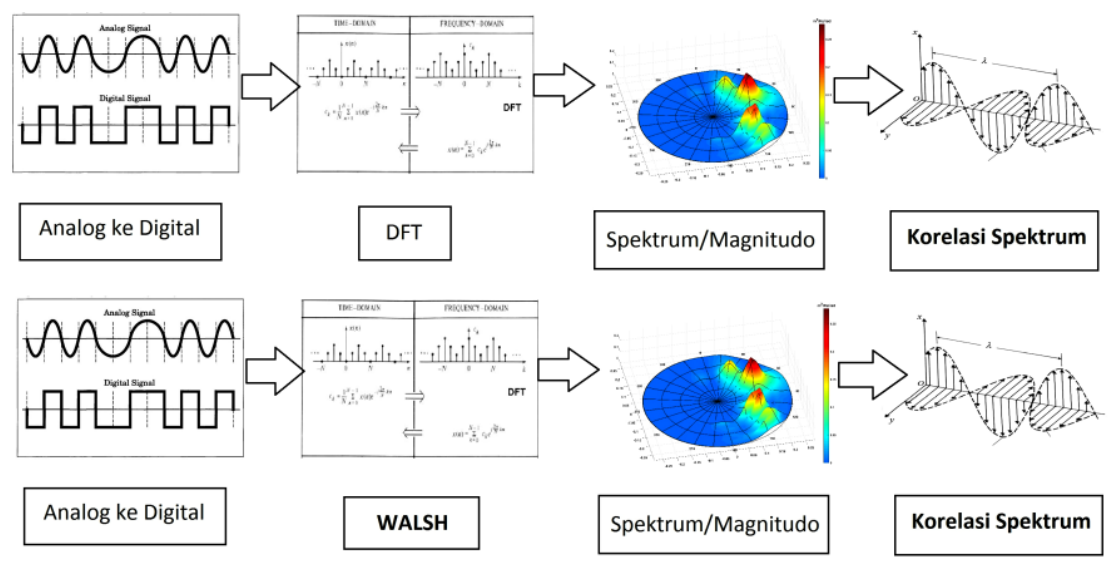

\section{Gambar 1. Skema Sistem Pengujian Pola Suara}

Proses sistem diawali dengan mengambil suara analog dan direkam menjadi suara digital pada domain waktu, selanjutnya DFT menggeser sinyal-sinyal pada domain waktu tersebut menjadi sinyal-sinyal pada domain frekuensi, yang selanjutnya dilakukan perhitungan spektrum atau magnitudo. Nilai-nilai spektrum inilah yang akan diajukan nilai referensi yang akan dikorelasikan dengan nilai spektrum suara pengujian.

Untuk mempertegas operasional dari kerja pada blok skema sistem, maka diperlukan diagram operasional flowchart. Berturutturut gambar 2 dan 3 mengilustrasikan flowchart Transformasi Mellin dan Transformasi Walsh. 


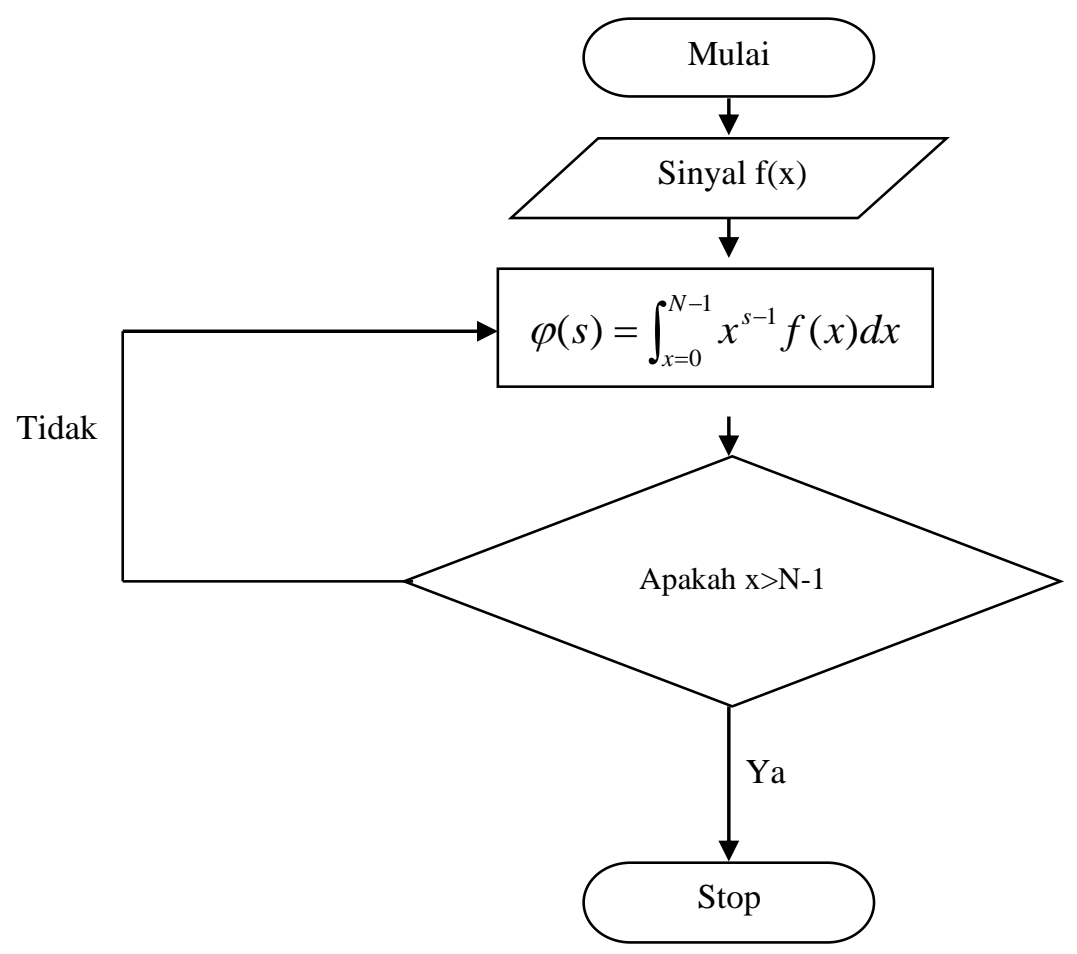

Gambar 2. Diagram Alir Transformasi Mellin 


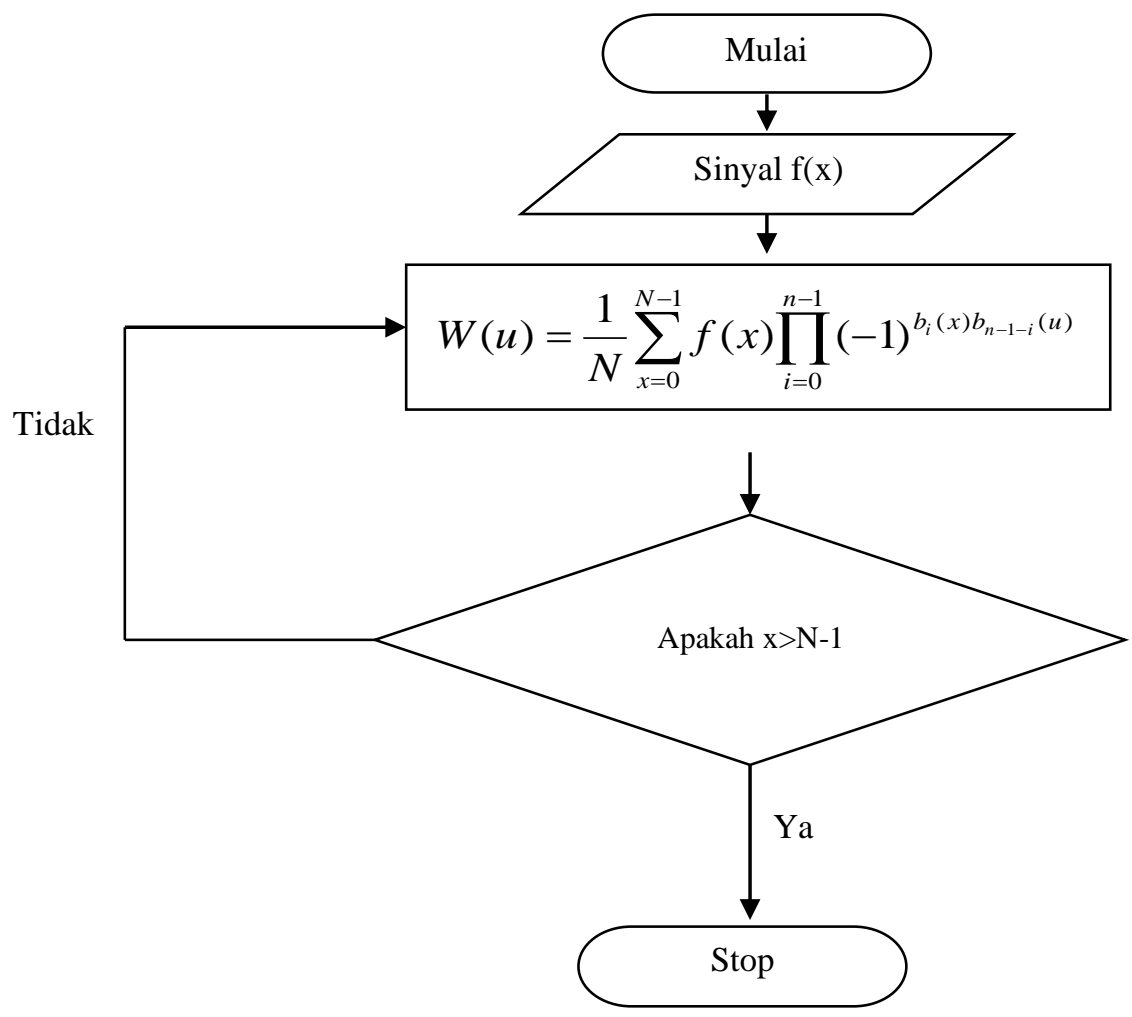

Gambar 3. Diagram Alir Transformasi Walsh

\section{Hasil dan Pembahasan}

Pengukuran unjuk kerja sistem dilakukan dengan berbagai tingkatan jumlah pelatihan untuk kedua transformasi. Berbagai hasil unjuk kerja sistem disajikan pada tabel 1 dan tabel 2. 
Sistem Waktu Nyata Pengujian Hafalan Ayat-Ayat Suci Al Quran Secara Eksponensial dan Nonsinusoidal

Tabel 1 Hasil Unjuk Kerja Sistem Menggunakan Transformasi

Mellin

\begin{tabular}{lllll}
\hline $\begin{array}{l}\text { Jumlah } \\
\text { Suara } \\
\text { Pelatihan }\end{array}$ & $\begin{array}{l}\text { Jumlah } \\
\text { Suara }\end{array}$ & $\begin{array}{l}\text { Jumlah } \\
\text { Pengujian }\end{array}$ & $\begin{array}{l}\text { False } \\
\text { yang benar }\end{array}$ & $\begin{array}{l}\text { Detection } \\
\text { Pate } \\
\text { Rate }\end{array}$ \\
\hline 25 & 100 & 60 & 0,4 & 0,6 \\
50 & 100 & 67 & 0,33 & 0,67 \\
75 & 100 & 85 & 0,15 & 0,85 \\
100 & 100 & 90 & 0,1 & 0,9 \\
\hline
\end{tabular}

Tabel 2 Hasil unjuk kerja sistem menggunakan Transformasi

Walsh

\begin{tabular}{lllll}
\hline $\begin{array}{l}\text { Jumlah } \\
\text { Suara }\end{array}$ & $\begin{array}{l}\text { Jumlah } \\
\text { Pelatihan }\end{array}$ & $\begin{array}{l}\text { Jumlah } \\
\text { Pengujian }\end{array}$ & $\begin{array}{l}\text { Palse } \\
\text { yang benar }\end{array}$ & $\begin{array}{l}\text { Detection } \\
\text { Pasitive } \\
\text { Rate }\end{array}$ \\
\hline 25 & 100 & 50 & 0,5 & 0,5 \\
50 & 100 & 59 & 0,41 & 0,59 \\
75 & 100 & 70 & 0,3 & 0,7 \\
100 & 100 & 82 & 0,18 & 0,82 \\
\hline
\end{tabular}

\section{Kesimpulan}

Dari hasil unjuk kerja yang ditampilkan pada tabel 1 dan 2, menunjukkan bahwa Transformasi Mellin memiliki nilai rate 0,9 dan Transformasi Walsh memiliki nilai rate 0,82 . Dengan kata lain Transformasi Mellin sedikit lebih unggul dalam keakuratan unjuk kerjanya dibandingkan Transformasi Walsh.

Untuk peningkatan efisiensi pemakaian memori dan peningkatan keakuratan uji, peneliti mensarankan sebuah model algoritma yang lebih Fast Transform. 


\section{Daftar Pustaka}

A. Mertins, T. Mei, and M. Kallinger, "Room impulse response shortening/reshaping with infinity- and p-norm optimization," IEEE Trans. Audio, Speech, Lang. Process., vol. 18, no. 2, pp. 249-259, Feb. 2010.

D. Chan, A. Fourcin, D. Gibbon, B. Granstrom, M. Huckvale, G. Kokkinakis, K. Kvale, L. Lamel, B. Lindberg, A. Moreno, J. Mouropoulos, F. Senia, I. Trancoso, C. Veld, and J. Zeiliger, "EUROM - a spoken language resource for the EU," in Proc. European Conf. on Speech Communication and Technology, Sept. 1995, pp. 867-870.

Fadlisyah, Bustami, dan Ikhwanus. 2013. Pengolahan Suara., Penerbit Graha Ilmu.Yogyakarta.

Fadlisyah. 2018. Pengolahan Suara untuk DAK Qur'an., Modul dan Bahan kuliah Universitas Malikussaleh.

F. Talantzis and D. B. Ward, "Robustness of multichannel equalization in an acoustic reverberant environment," J. Acoust. Soc. Am., vol. 114, no. 2, pp. 833-841, 2003.

G. Harikumar and Y. Bresler, "FIR perfect signal reconstruction from multiple convolutions: minimum deconvolver orders," IEEE Trans. Signal Process., vol. 46, pp. 215-218, 1998.

H. Kuttruff, Room Acoustics, 4th ed. Taylor \& Frances, 2000.

ITU-T, Perceptual evaluation of speech quality (PESQ), an objective method for end-to-end speech quality assessment of narrowband telephone networks and speech codecs, International Telecommunications Union (ITU-T) Recommendation P.862, Feb. 2001.

J. Vanderkooy, "Aspects of MLS measuring systems," Journal Audio Eng. Soc., vol. 42, pp. 219-231, 1994.

K. Furuya and Y. Kaneda, "Two-channel blind deconvolution for non-minimum phase impulse responses," in Proc.IEEE Intl. 
Conf. on Acoustics, Speech and Signal Processing (ICASSP), 1997, pp. 1315-1318.

M. Miyoshi and Y. Kaneda, "Inverse filtering of room acoustics," IEEE Trans. Acoust., Speech, Signal Process., vol. 36, no. 2, pp. 145-152, Feb. 1988.

M. Kallinger and A. Mertins, "Multi-channel room impulse response shaping - a study," in Proc. IEEE Int. Conf. Acoust., Speech, Signal Processing, 2006.

N. D. Gaubitch and P. A. Naylor, "Equalization of multichannel acoustic systems in oversampled subbands," IEEE Trans. Audio, Speech, Lang. Process., vol. 17, no. 6, pp. 1061-1070, Aug. 2009.

P. A. Naylor and N. D. Gaubitch, Eds., Speech Dereverberation. Springer, 2010.

R. K. Martin, K. Vanbleu, M. Ding, G. Ysebaert, M. Milosevic, B. L. Evans, M. Moonen, and C. R. Johnson Jr., "Unification and evaluation of equalization structures and design algorithms for discrete multitone modulation systems," IEEE Trans. Signal Process., vol. 53, pp. 3880-3894, 2005.

R. Rado, "Note on generalized inverse of matrices," Proc. Cambridge Philos. Soc., vol. 52, pp. 600-601, 1956.

T. Hikichi, M. Delcroix, and M. Miyoshi, "Inverse filtering for speech dereverberation less sensitive to noise and room transfer function fluctuations," EURASIP Journal on Applied Signal Processing, vol. 2007, 2007.

W. Zhang, E. A. P. Habets, and P. A. Naylor, "On the use of channel shortening in multichannel acoustic system equalization," in Proc. Intl. Workshop Acoust. Echo Noise Control (IWAENC), Tel Aviv, Israel, Aug. 2010.

W. Zhang, A. W. H. Khong, and P. A. Naylor, "Adaptive inverse filtering of room acoustics," in Proc. Asilomar Conf. on Signals, Systems and Computers, 2008. 